\title{
¿HACIA DÓNDE, CUBA?
}

\section{Cliff DuRand*}

ReSUmen: Desde la década de los sesenta, Estados Unidos implementa una estrategia para descarrilar la Revolución cubana. La administración de Barack Obama ha aceptado que esa línea dura no ha funcionado, no obstan la política continúa interesada en que Cuba regrese al sistema capitalista. Obama pretende cambiar a Cuba no mediante un cambio de régimen sino apoyando a la pequeña burguesía cubana. El reconocimiento del gobierno cubano no implica la aceptación del sistema económico socialista. Esa estrategia aprovecha la apertura a los pequeños emprendimientos privados dentro de las recientes reformas cubanas. $\mathrm{Si}$ bien no se abandona el papel central del Estado, las reformas implican un desplazamiento del modelo del Estado socialista hacia un modelo con una sociedad civil mucho más activa.

palabras Clave: socialismo, sociedad civil, cooperativas, Cuba, Estados Unidos.

* Investigador asociado del Centro para la Justicia Global y autor/editor del libro Recreating Democracy in a Globalized State.

Traducción por Ercilia Sahores. 
ABSTRACT: Beginning in the 1960s, the United States has implemented a strategy to drail the Cuban Revolution. The Administration of Barack Obama now accepts that this approach has not worked, although the policy continues to seek Cuba's return to the capitalist system. Obama intends to change Cuba not through regime change but rather by supporting Cuba's petty bourgeoisie. The us A's recognition of the Cuban government does not imply an acceptance of the socialist economic system. This strategy seeks to take advantage of the opening to small private entrepreneurs within recent Cuban reforms. While not abandoning the central role of the State, the reforms imply a displacement of the State socialist model toward a model in which civil society is more active.

KEY WORDS: socialism, civil society, cooperatives, Cuba, United States. 
L a estrategia de Estados Unidos para desarticular la Revolución cubana fue desplegada durante la era de Eisenhower, en abril de 1960, y en los Lineamientos del Departamento de Estado, de la siguiente manera:

Se deben tomar con la mayor celeridad todas las medidas posibles para debilitar la economía de Cuba [...] [;] una vía de acción que de manera hábil y discreta, progrese hacia la negación de dinero y suministros a Cuba, que disminuya el salario real y nominal, que traiga consigo hambre, desesperación y el derrocamiento del gobierno (Oficina del Historiador, Oficina de Asuntos Públicos, Departamento de Estado de los Estados Unidos; John P. Glennon et al., 1991: 885).

Ahora, 55 años más tarde, la administración de Barack Obama ha aceptado que esta línea dura no ha funcionado en Cuba. En todo caso, el cambio de régimen no tendría como resultado una sociedad estable (basta ver el caso de Irak, Afganistán, Libia, etcétera).

Sin embargo, el objetivo básico de la política estadounidense continúa siendo el mismo, es decir, lograr que Cuba regrese a la órbita del capitalismo. Lo novedoso en la estrategia del presidente Obama es cambiar a Cuba no a través de una transformación del régimen, sino mediante el apoyo a la pequeña burguesía cubana. El reconocimiento del gobierno cubano no implica la aceptación del sistema económico socialista. Nuestra élite aún se cree con derecho a reformular la sociedad cubana según sus propios deseos.

Esta estrategia se aprovecha de la apertura a los pequeños emprendimientos privados dentro de las recientes reformas cubanas. Si bien no se abandona el papel central del Estado, las reformas implican un desplazamiento del modelo del Estado socialista hacia un modelo con una sociedad civil mucho más activa. La sección de apertura de los Lineamientos sobre el Modelo de Administración Económica sacan a la luz el cambio de relación entre Estado y sociedad. 
El modelo administrativo reconoce y promueve, al igual que la empresa estatal socialista, que es el método principal de la economía nacional, las modalidades autorizadas legalmente de inversión extranjera (empresas mixtas, acuerdos contractuales internacionales, entre otros), cooperativas, campesinos agricultores, arrendatarios de tierras pertenecientes al Estado, trabajadores cuentapropistas y otras modalidades, las cuales, en su conjunto, deben contribuir a incrementar la eficiencia [Lineamientos, núm. 2].

Lo que Cuba busca es una economía mucho más mixta; 84 por ciento de la fuerza laboral cubana ha trabajado para el Estado. Esto ha llevado a una falta de motivación y exceso de personal. El Estado cubano ha sido el mayor empleador de última instancia; podría decirse, en realidad, que de primera instancia. Como resultado, al menos 1 millón de trabajadores estatales resultan redundantes y el Estado no puede afrontar sus costos. De esta manera, los despidos son masivos y esta fuerza laboral busca volver a colocarse en el sector no estatal de la economía. Este creciente sector abarca a los cuentapropistas y las cooperativas. El pequeño sector de emprendimientos privados, que fuera expropiado en 1968, está siendo recreado para absorber a los trabajadores estatales. Hay un reconocimiento de que existe un lugar para la pequeña burguesía dentro del socialismo; el Estado no debe ni puede hacerlo todo. Muchas actividades económicas pueden quedar libradas a emprendedores individuales en tanto estén regulados y paguen sus impuestos de manera que la pequeña burguesía no se convierta en una gran burguesía. Tal como está expresado en los Lineamientos: «En las formas de gestión no estatales, no se permitirá la concentración de la propiedad en personas jurídicas o naturales».

La renovación del socialismo que está teniendo lugar en Cuba es un esfuerzo por revitalizar la sociedad civil y abrir espacios para la iniciativa fuera del Estado. Se calcula que en los próximos años, el sector no estatal de la economía, consistente en cooperativas y negocios privados, brindará 35 por ciento del empleo y constituirá, junto con empresas extranjeras y fusiones, 45 por ciento del producto bruto interno. 
Dirigiéndose al problema de la falta de iniciativa de los trabajadores bajo el socialismo de Estado, estas reformas están desencadenando nuevas energías productivas que levantarán la economía. Pero más allá de eso, reemplazarán la participación pasiva del socialismo de Estado con una participación proactiva, más apropiada para un socialismo democrático. Esto implica una nueva relación entre el Estado y la sociedad civil.

La distensión de las relaciones entre Obama y Cuba representa un nuevo desafío para la Revolución. Si bien el tardío reconocimiento de que Cuba posee su propio gobierno es elogiable, existe otro aspecto que pasa inadvertido de la nueva política de Estados Unidos hacia Cuba. Ésta se basa en numerosas medidas para ayudar en el desarrollo de una incipiente clase capitalista del sector financiero privado. Una lectura cuidadosa de las nuevas regulaciones de Estados Unidos revela un esfuerzo consensuado de dirigir recursos a emprendedores dentro de Cuba a través de remesas, ayuda material, capacitación e intercambio.

Por ejemplo, el nivel de remesas permitido ha sido aumentado de manera que bride un mayor financiamiento para la iniciativa privada. Un comunicado de prensa de la Casa Blanca del 17 de diciembre de 2014 dice: «Los niveles de remesas se incrementarán de 500 a 2,000 dólares por cuatrimestre en concepto de donativo general de remesas hacia los nacionales de Cuba (quedan excluidos ciertos funcionarios del gobierno o del partido comunista)». De igual manera, el Departamento de Comercio de Estados Unidos anunció en marzo que las exportaciones de equipo y el abastecimiento hacia Cuba están permitidos, de la misma manera que las importaciones desde Cuba, en tanto y en cuanto la entidad cubana sea independiente del gobierno. Estados Unidos busca aumentar las «oportunidades para el empleo cuentapropista y la propiedad privada [...] fortaleciendo la sociedad civil independiente». La Casa Blanca explícitamente dice: «Nuestros esfuerzos están dirigidos a promover la independencia del pueblo cubano, para que no tengan que depender del Estado cubano».

Muchos observadores esperan una invasión de empresas estadounidenses en Cuba; pero se olvidan que el embargo continúa. Obama ha hecho más laxos algunos de sus aspectos, pero terminarlo requeriría una 
acción de parte del Congreso, algo poco probable en el futuro cercano. En todo caso, Cuba ha estado muy abierta a la inversión extranjera en los últimos 20 años. Recientemente, promulgó una nueva ley sobre inversión extranjera diseñada para atraer inversiones del exterior. Las corporaciones estadounidenses esperan poder conseguir un pedazo del pastel que con el embargo les fue negado. Pero una vez que logren entrar, Cuba les aplicará, sin dudas, las mismas limitaciones que aplica a toda inversión extranjera. Esto implica que las corporaciones deberán asociarse con el Estado cubano por un periodo específico; Cuba no va a abandonar su soberanía.

Lo que posiblemente sea el factor que transforme a la sociedad cubana es el creciente flujo de dinero hacia emprendedores privados individuales con el afán de crear el germen de una nueva clase capitalista. Este método se aprovecha de la apertura cubana hacia un sector económico no estatal.

Pero este sector no estatal incluye también a las cooperativas, que son una forma socialista de propiedad. Si bien Cuba ha contado con cooperativas desde los primeros años de la Revolución, éstas habían sido limitadas al sector agrícola. Como parte de las reformas, en diciembre de 2012, la Asamblea Nacional promulgó una ley de cooperativas urbanas que sienta las bases legales para éstas. He aquí algunas de sus principales disposiciones:

- Una cooperativa debe estar compuesta por al menos tres socios, pero puede tener hasta 60 o más. A cada socio le corresponde un voto. Como toda empresa autogestionada, las cooperativas deben contar con mecanismos democráticos de toma de decisiones.

- Las cooperativas son independientes del Estado. Responden al mercado. Esto es para sobrepasar algunos obstáculos limitantes de las antiguas cooperativas agrícolas.

- Las cooperativas pueden hacer negocios con compañías privadas y estatales. En la mayoría de los casos fijarán sus propios precios, excepto cuando dichos precios sean fijados por el Estado. 
- Algunas cooperativas serán empresas estatales convertidas, como por ejemplo los restaurantes. Podrán tener contratos de arrendamiento renovables de 10 años y no pagarán renta durante el primer año si realizan mejoras.

- Otras serán cooperativas de nuevos emprendimientos.

- Habrá cooperativas de segundo grado, que son asociaciones de otras cooperativas.

- Se capitalizarán a través de préstamos bancarios, un nuevo Ministerio de Finanzas financiado por las cooperativas y contribuciones de sus socios. Las contribuciones de los socios serán tomadas como préstamos (no acciones) y no generarán votos adicionales. Los préstamos se pagarán con el producto de las ganancias.

- Las cooperativas deberán pagar impuestos sobre el lucro y pagarán el seguro social a sus socios.

- La distribución de las ganancias será determinada por los socios una vez que hayan apartado un fondo de reservas.

- Las cooperativas pueden contratar empleados asalariados de manera temporal (hasta 90 días). Luego de 90 días, al empleado temporal se le debe ofrecer una membresía para que se convierta en socio o dejarlo ir. El tiempo de trabajo temporal total no puede superar el 10 por ciento del total de días laborables del año. Esto da a las cooperativas una flexibilidad para contratar trabajadores extra por temporada o como respuesta a un aumento de la demanda del mercado, pero previene cualquier tipo de explotación colectiva de trabajadores asalariados.

A partir de julio de 2014 se han autorizado 498 cooperativas urbanas. Existen otras cooperativas que se encuentran en funcionamiento pero no han sido reconocidas como entidades legales. Este es un gran paso hacia delante para Cuba. Los socios de una cooperativa tienen un incentivo para lograr el éxito. La cooperativa está librada a su propia suerte y puede prosperar o hundirse. El ingreso y la seguridad de cada socio depende del colectivo y cada uno posee el mismo derecho a voto en la Asamblea General, en la cual se determinan las políticas de la 
cooperativa. En un estudio realizado en 29 nuevas cooperativas (Piñeiro Harnecker, en prensa, a) encontró que los ingresos han aumentado en promedio tres veces y tanto como siete veces más.

Una de las nuevas cooperativas que visité en junio de 2014 fue un pequeño bar y restaurante en una sección pobre del centro de La Habana. La cooperativa bar Okinawa, antiguamente una empresa estatal, posee cinco socios. Se había constituido como cooperativa ocho meses atrás y el presidente me dijo que uno de los principales beneficios era poder tomar sus propias decisiones; fue elegido para su puesto por sus compañeros trabajadores. Resulta interesante que el antiguo administrador, también integrante de la cooperativa, no fue elegido para liderar la nueva cooperativa.

La motivación suscitada por este empoderamiento fue demostrada radicalmente por los socios de una cooperativa de construcción autoorganizada con los que me reuní en el Instituto de Filosofía. Estaban haciendo reparaciones en el edificio del Instituto, que debido al colapso de su cielorraso en el primer piso dos años atrás, hacía imposible el usufructo de la mayor parte de la propiedad. Una compañía de construcción estatal había trabajado en el edificio por dos años, con muy poco éxito. Pero en poco tiempo y gracias a esta nueva cooperativa, el edificio del Instituto ya se veía mucho mejor. Nuestro grupo tenía cita en el Instituto el lunes por la mañana. Entre el jueves anterior y esa mañana, el cableado en el cielorraso había sido renovado y ya estaba revocado. A la siguiente semana, el personal del Instituto regresó a las oficinas en el segundo piso. Los 20 socios de la cooperativa están motivados por el hecho de que por primera vez, controlan su trabajo. Toman sus propias decisiones. Ésta es una poderosa demostración de la fortaleza de las cooperativas.

Con la promoción de las nuevas cooperativas en Cuba, estamos siendo testigos de cómo el poder constitutivo del Estado alimenta el poder constitutivo de la sociedad civil. Las cooperativas son una forma socialista de propiedad bajo una gestión democrática; como tales, tienen la virtud de promover valores socialistas, responsabilidad, toma de decisiones democráticas, coo- 
peración y solidaridad social. Son pequeñas escuelas de socialismo. Incorporan el socialismo en la vida diaria de la gente trabajadora, engendrando una sociedad civil socialista.

Es de este modo que contrastan con la nueva pequeña burguesía, con las pequeñas y medianas empresas privadas que ahora también están siendo formadas por los cuentapropistas. Una pequeña burguesía es vista como compatible con el socialismo; compatible en tanto sea regulada $y$ sujeto de impuestos para evitar que se convierta en gran burguesía. Las grandes desigualdades, producto del ingreso y la acumulación de la riqueza deben ser evitadas, ésta es una nota de advertencia hecha en los Lineamientos. Pero si es claro que una pequeña burguesía es compatible con el socialismo cuando se la limita, no por ello es socialista.

Las cooperativas sí son socialistas. Representan a los productores asociados uniéndose, a pequeña escala, para gobernar su vida laboral de manera democrática. Es a este tipo de transición socialista a la que debe apuntar Cuba. Con la apertura de nuevas cooperativas, el socialismo de Estado cubano está encontrando un nuevo camino. El socialismo no se puede construir de arriba hacia abajo exclusivamente con el poder estatal; tiene que estar enraizado en la base de la sociedad, con la gente común y corriente. Sus valores, prácticas y relaciones sociales deben estar cimentadas en la vida cotidiana de la gente, en los lugares donde viven y trabajan. Ésta es la virtud de las cooperativas. De esta manera, las cooperativas pueden ayudar a construir un socialismo que sea irreversible.

Si un orden social pretende ser sustentable en el largo plazo, debe estar arraigado en el carácter de las personas. Sus valores, sus sensibilidades, sus entendimientos tácitos, su misma subjetividad debe estar en consonancia con las instituciones. La transición socialista es un proceso que necesita de personas con un carácter socialista para poder continuar. Las relaciones sociales de las cooperativas ayudan a construir este tipo de carácter entre sus integrantes.

Es por esto que es sumamente importante la promoción de las cooperativas. Los beneficios de las mismas deben ser publicitados y se debe poner a disposición diferentes tipos de capacitación en cooperativismo. 
Debe existir una red de promotoras que comuniquen a la sociedad, a la manera de los trabajadores de alfabetización a principios de la década de los sesenta, para que enseñen sobre la vía cooperativa. Esto es precisamente lo que está haciendo el Instituto Cubano para la Filosofía en el centro de la Habana, en colaboración con nuestro Centro para la Justicia Global, que desde hace años ofrece talleres sobre cooperativismo en México.

En este punto de inflexión en los esfuerzos cubanos para construir el socialismo con audacia, existe una carrera por el alma de Cuba entre el movimiento cooperativo y la creciente iniciativa privada. ¿Cuál de los dos empleará la mayor parte del tercio de la población que no está empleada por el Estado? ¿Serán empresas socialistas o protocapitalistas? El gobierno cubano está favoreciendo el desarrollo de cooperativas. Obama está promoviendo la iniciativa privada, lo cual es una estrategia política inteligente de su parte. Pero como me dijo un amigo cubano, «la nuestra es una revolución inteligente, también. Somos un pueblo inteligente».

Existen claramente nuevos desafíos para la Revolución cubana. ¿Cómo puede limitarse a una pequeña burguesía y al mismo tiempo aprovechar su dinamismo? Existen algunas medidas que pueden aplicarse, como:

- Promoción de la responsabilidad social por parte de la iniciativa privada, quizás regulada por la comunidad local.

- Un impuesto gradual sobre las ganancias de las empresas.

- Derechos de importación elevados sobre suministros para empresas privadas.

- Requerimiento de un salario mínimo generoso.

- Sindicalización de empleados y regulación fuerte de derechos de los trabajadores.

+ Limitación del número de trabajadores asalariados permitidos en emprendimientos privados.

- Establecer que cuando una iniciativa privada crezca hasta alcanzar un determinado tamaño, se convierta en cooperativa para que todos los empleados puedan compartir las ganancias y la toma de decisiones. 
Es necesario desarrollar un régimen regulatorio para el sector privado. El Estado parece no tener ninguna urgencia en hacer esto y algunos se quejan de que la cancha está abierta para todos y no hay reglas. Otros ven esta falta de regulación como una virtud, señalando hacia las pequeñas y medianas empresas privadas y a la inversión extranjera como los elementos claves para el necesario crecimiento económico. Existen tendencias en conflicto hoy en día entre los hacedores de políticas y sus asesores (Piñeiro, 2012).

Pero existen también fuertes defensores de las cooperativas como la clave para el futuro de Cuba. Camila Piñeiro, del Centro de Estudios para la Economía Cubana de la Universidad de La Habana es una defensora, quien argumenta que:

estas organizaciones socioeconómicas están mejor preparadas que la iniciativa privada para llevar a cabo una gestión económica que satisfaga las necesidades sociales y las relaciones sociales [...] [;] facilitan la satisfacción de las necesidades materiales y espirituales de sus integrantes, su desarrollo humano pleno, permiten relaciones sociales socialistas basadas en igualdad, solidaridad, democracia y justicia.

Es por estas razones que el Estado le da un trato preferencial a las cooperativas sobre otros emprendimientos no estatales (Piñeiro Harnecker, en prensa, b).

Es por ello que el objetivo de Obama es ayudar a que los emprendimientos privados ocupen la mayor cantidad posible del espacio económico no estatal. Sin embargo, sus nuevas regulaciones se aplican a cualquier entidad que sea «independiente del gobierno», esto incluye las cooperativas. Por ello es que ahora es legal que las organizaciones en Estados Unidos envíen donaciones a las cooperativas cubanas, así como material de ayuda o impartan capacitaciones o cursos educativos e inclusive que importen bienes procedentes de cooperativas cubanas, otorgándoles así un mayor mercado para sus productos. Quienes se consideran progresistas deben pensar seriamente acerca de cómo podemos apoyar el crecimiento de cooperativas genuinamente democráticas y 
gestionadas por los trabajadores. Cuba está lista para ello y Obama ha abierto el camino para que aceptemos esta oportunidad única.

La estrategia de Obama es cambiar Cuba; no a través de un cambio de régimen, sino a través de la promoción del capitalismo dentro del país, con el apoyo de una pequeña burguesía. Después de todo, el objetivo fundamental de las políticas de Estados Unidos siempre ha sido lograr que Cuba regrese a la órbita del capitalismo. Hoy nos encontramos ante un escenario único; un Estado socialista está promoviendo de manera activa el desarrollo de cooperativas, regresando así el poder eonómico al pueblo, a nivel de base. Existe un rejuvenecimiento de la sociedad civil, de una sociedad civil socialista. Es un llamado a nuestra solidaridad para que la ayudemos a moverse hacia el camino de un socialismo para el siglo XXI.

\section{BIBLIOGRAFÍA}

Oficina del Historiador, Oficina de Asuntos Públicos, Departamento de Estado de los Estados Unidos; John P. Glennon et al., (eds.) (1991), Foreign Relations of the United States, 1958-1960, vol. VI, Cuba-Washington, GPO.

Piñeiro Harnecker, Camila (2012), «Visiones sobre el socialismo que guían los cambios actuales en Cuba», Temas. (en prensa), Un acercamiento a las cooperativas en Cuba. (en prensa), «Cuba's Cooperatives: Their Contribution to Cuba's New Socialism», en Cliff DuRand (ed.), Moving Beyond Capitalism. 